\title{
Article \\ Proof-of-Concept Preclinical Use of Drosophila melanogaster in the Initial Screening of Immunomodulators
}

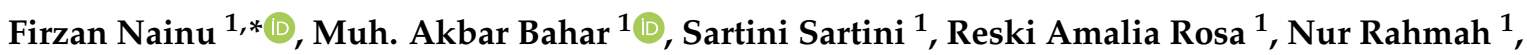 \\ Reski Amelia Kamri ${ }^{1}$, Nur Rahma Rumata ${ }^{2}$, Risfah Yulianty ${ }^{1}$ and Elly Wahyudin ${ }^{1}$
}

1 Faculty of Pharmacy, Hasanuddin University, Makassar 90245, Sulawesi Selatan, Indonesia; akbarbahar@unhas.ac.id (M.A.B.); sardj@farmasi.unhas.ac.id (S.S.); reskiamaliarosa05@gmail.com (R.A.R.); nurrahmah840@gmail.com (N.R.); reski272@gmail.com (R.A.K.); risfah@yahoo.com (R.Y.); ellywahyudins@gmail.com (E.W.)

2 Sekolah Tinggi Ilmu Farmasi Makassar, Makassar 90242, Sulawesi Selatan, Indonesia; n.rumata@yahoo.com

* Correspondence: firzannainu@unhas.ac.id; Tel.: +62-821-9131-0384

check for

updates

Citation: Nainu, F.; Bahar, M.A.; Sartini, S.; Rosa, R.A.; Rahmah, N.; Kamri, R.A.; Rumata, N.R.; Yulianty, R.; Wahyudin, E. Proof-of-Concept Preclinical Use of Drosophila melanogaster in the Initial Screening of Immunomodulators. Sci. Pharm. 2022, 90, 11. https://doi.org/ 10.3390/scipharm 90010011 Academic Editor: Roman B. Lesyk

Received: 31 December 2021

Accepted: 3 February 2022

Published: 8 February 2022

Publisher's Note: MDPI stays neutral with regard to jurisdictional claims in published maps and institutional affiliations.

Copyright: (C) 2022 by the authors. Licensee MDPI, Basel, Switzerland. This article is an open access article distributed under the terms and conditions of the Creative Commons Attribution (CC BY) license (https:// creativecommons.org/licenses/by/ $4.0 /)$.

\begin{abstract}
Drug discovery is a complex process, and the use of a comprehensive approach is deemed necessary to discover new chemical entities with novel mechanisms of action. This research was carried out to determine whether Drosophila melanogaster can serve as an appropriate model organism in the initial screening of drug candidates with immunomodulatory activities. To test this, we performed phenotypic assay and molecular analysis to investigate the immunomodulatory activities of aspirin, dexamethasone, curcumin, and epigallocatechin gallate (EGCG), that have been reported to yield such effects in the mammalian model system. In vivo survival analysis demonstrated that all drugs/compounds were relatively safe at the tested concentrations. In the infection assay, curcumin and EGCG showed a protective signature to bacterial infection in flies lacking Toll-mediated immune responses. Furthermore, dexamethasone and aspirin, drugs with immunosuppressive activity, could improve the survival of $P G R P-L B^{\Delta}$ mutant flies with hyperactivated immune system. These phenotypes were supported by RT-qPCR-based molecular analysis, revealing that drugs/compounds used in this study could modulate the expression level of genes related to the immune system. In conclusion, while curcumin and EGCG could promote the improvement of fly survival against infection, aspirin and dexamethasone were able to suppress overactivation of immune responses in D. melanogaster. These results are in line with the ones observed in the mammalian model system, further emphasizing the notion that flies would serve as a prospective model organism in the initial screening of drug candidates for their immunomodulatory activities prior to further checking in the mammalian animal models. In the end, this will reduce the use of mammalian animal models for preliminary experiments in an effort to discover/repurpose drugs with immunomodulatory activity.
\end{abstract}

Keywords: fruit flies; immunomodulators; in vivo; drug discovery; drug repurposing

\section{Introduction}

Drug discovery is a complex process, and the use of a comprehensive approach is deemed necessary to discover new chemical entities with novel mechanisms of action from nature [1]. With regard to this, the current approach used in the discovery of new immunomodulators is a combination of in silico, in vitro, and in vivo pre-clinical experiments in appropriate animal models prior to clinical testing in humans [2,3].

Immunity is defined as the action of host immune defenses against diverse types of pathogens and other non-self-entities capable of causing immune-related disorders [4]. The immune system plays an important role in health; a host with impaired immunity will be more susceptible to severe infections that may culminate in a life-threatening event [4]. Therefore, stimulation of host immune responses to certain antigens/pathogenic cues through vaccination is the most effective method of protecting a host from infection [4]. 
In addition, activation of host innate cellular and humoral immunity by agonists with immunomodulatory activities has been a pertinent approach to developing a rapid and broad protective effector against pathogenic microbes [3].

In contrast, problems related to unwanted immune activation such as autoinflammatory/autoimmunity disorders occur due to catastrophic failure in the self and non-selfrecognition [4]. Immunosuppressive agents with anti-inflammation feature can be used to tackle the problems. A common phenotypical effect of such drugs is achieved by the inhibition of inflammation, either by direct inhibition of receptors/molecules responsible in the stimulation of inflammation or by downregulating the expression of pro-inflammatory cytokines [5]. Therefore, drug candidates with such potentials would play distinct roles in the treatment of hyperimmune activation-related disorders. However, with our current approach, discovering new chemical entities with novel mechanisms of action seems challenging.

The immune system of humans shows similarities with that of animal models, such as mice, rats, and fruit flies (Drosophila melanogaster) [6-8]. Drosophila melanogaster has similar signaling pathways to the human immune system, such as Toll and IMD, which are linked to the transcription factor nuclear factor-kB (NF-kB), JAK/STAT, apoptosis, autophagy, and RNA interference (RNAi) [7]. As a model organism, the fruit fly offers numerous advantages for use as an in vivo system in the screening of immune-related drugs [9]. In addition, the fruit fly is easy and relatively cheap to nurture compared to other model animals $[6,9]$ and female flies can produce a large number of offspring in a short period of time enabling large-scale experiments within a short duration. Furthermore, fruit flies have a short life span (approximately 2-3 months) and can be used in research without requiring any ethical clearance [9].

One of the most important points of using Drosophila melanogaster as a model organism in immunology-related research is the availability of mutant and/or transgenic lines that can be used as immunodeficient models that lack certain immune phenotypes [9]. In addition, the absence of an adaptive immune system in fruit flies $[7,8]$ shall provide an ideal in vivo condition to study the pharmacological regulation of innate immunity at the cellular and molecular levels in order to discover potential candidates with immunostimulatory or immunosuppressive activities. In addition to that, the use of fruit flies as a model organism in drug discovery has been explored by many groups worldwide. In fact, translational relevance of $D$. melanogaster in drug discovery and drug repurposing has been suggested as many drugs yielded similar pharmacological effects in both fruit flies and humans [10]. While this model organism is not yet widely used in the drug discovery and drug repurposing efforts, the accumulation of publications in the last two decades suggested the potential of this tiny insect in the drug discovery platform due to its genomic simplicity, and the fact that it is easy to use, presents fewer ethical issues and has excellent financial considerations $[9,10]$. Hence, we proposed the use of D. melanogaster as a model organism to screen and examine the potential effect of drug candidates with immunomodulatory activities.

In this study, we carried out experiments using two FDA-approved drugs, aspirin (acetylsalicylic acid, ASA) and dexamethasone, which have been reported to yield immunosuppressive effects in several animal models including humans [11-18]. We ought to examine whether a similar immunoinhibitory effect can be observed in our D. melanogaster model system. In addition, we also performed in vivo experiments to examine whether certain compounds that have been widely investigated in the field of immunology can also modulate the fly immune system. Therefore, we decided to assess the immunomodulatory effect of curcumin and epigallocatechin gallate (EGCG). However, it is important to note that both curcumin and EGCG have been intriguingly reported to exert both immunostimulatory and immunosuppressive effects in the mammalian animal models [19-23]. As there is no cue yet on whether these compounds can exert any effects on the fly immune system, we believe that the use of compounds with such dual intriguing effects are suitable to provide insights into the potential of the D. melanogaster platform to investigate the immunopharmacological effect of drug candidates. 


\section{Materials and Methods}

\subsection{Fly Stocks and Maintenance}

Drosophila melanogaster genotype Oregon R (wild type) and several mutant flies lacking Toll-mediated immune system ( $p s h[1] ; ; \operatorname{modSP}[\mathrm{KO}]$ or with NF-kB hyperactive immune system $\left(P G R P-L B^{\Delta}\right)$ were obtained from the Laboratory Host Defense and Responses (Kanazawa University, Japan). All flies were maintained in normal fly food and stored at $25^{\circ} \mathrm{C}$ for more than 20 inbred generations in our laboratory.

\subsection{Bacterial Strain and Fly Infection Experiment}

Bacterial infection experiments were carried out using a 24-hour-old culture of Staphylococcus aureus ATCC 29213. Staphylococcus aureus was used as the pathogen that can inflict a serious outcome on the mutant of $D$. melanogaster lacking Toll-mediated immune responses (psh[1];;modSP[KO]). The bacterial inoculum was collected, washed carefully with phosphate-buffered saline (PBS), diluted equal to $0.5 \mathrm{McFarland}$ density, and suspended in PBS before use. Fly infection experiment was performed on the thorax of D. melanogaster by using the pricking method, as described previously [24-27]. Briefly, adult male fruit flies that were 4-7 days old (30 flies per group of treatment) were pricked using a tungsten fine needle that had been previously dipped in the $S$. aureus culture (100-fold dilution of $0.5 \mathrm{McF}$ arland density). All pricked flies were maintained at $29^{\circ} \mathrm{C}$ and subjected to assessment on fly survivorship, as described previously [24-27].

\subsection{Survival Assay of Drosophila Melanogaster}

The maximum lifespan of all fly genotypes was assessed before drug treatment. This is very important before conducting a survival test in the presence of the test sample. In this study, fly survival analysis was performed in the presence or absence of drug candidates. Flies aged 2-4 (PGRP-LB $\left.{ }^{\Delta}\right)$ or 4-7 days old (Oregon R and $\left.p s h[1] ; ; \operatorname{modSP}[K O]\right)$ post exclusion from the pupal cases were used. Flies were maintained in the Drosophila vials that contained fly food with drugs/compounds at certain concentrations. Flies were transferred every three days to new vials containing freshly prepared normal fly food (in the presence or absence of drugs/compounds) and stored at $25{ }^{\circ} \mathrm{C}$ until the end of the experiments. In some experiments, infection using $S$. aureus was carried out in the presence or absence of drug candidates. For the infection experiment, flies were maintained at $29{ }^{\circ} \mathrm{C}$ until the end of the experiments. In the assessment of fly survival during infection, $S$. aureus-pricked flies were maintained in the presence or absence of drug candidates and the number of surviving/dead flies in each group was recorded daily during the experiment.

\subsection{Gene Expression Analysis}

All fly lines were collected separately and transferred to the allocated vials (15 male flies). In this assay, RNA isolation was carried out using a minimum of five live flies. Total RNA from the whole body of flies was extracted using RNA Isolation System (Promega) according to the manufacturer's protocol. The levels of Drosomycin (Drs) and Diptericin (Dpt) expression were quantitatively determined using the reverse transcriptase quantitative PCR (RT-qPCR) method. The RT-qPCR assay was performed in a $20 \mu \mathrm{L}$ reaction volume using GoTaq ${ }^{\circledR}$ 1-Step RT-qPCR System (Promega) as per the manufacturer's instructions. To confirm that only the expected product had been amplified, a standard melt curve analysis was carried out in every run. Using a similar RT-qPCR protocol, the RNA level of host ribosomal protein $r p 49$ (used as an internal control) was examined by using one set of $r p 49$ primer (sequence of $r p 49$ forward primer: 5'-AGA TCG TGA AGA AGC GCA CCA AG-3' (23-mer) and the sequence of $r p 49$ reverse primer: 5'-CAC CAG GAA CTT CTT GAA TCC GG-3' (19-mer). Rotor-Gene Q thermal cycler (Qiagen, Germany) was operated with the following profile: $37^{\circ} \mathrm{C}$ for $15 \mathrm{~min}, 95^{\circ} \mathrm{C}$ for $10 \mathrm{~min}$, and 40 cyclic repeats of $95^{\circ} \mathrm{C}$ for $10 \mathrm{~s}$ and $60{ }^{\circ} \mathrm{C}$ for $30 \mathrm{~s}$, and $72{ }^{\circ} \mathrm{C}$ for $30 \mathrm{~s}$. 


\subsection{Data Analysis}

Results obtained from at least three independent biological replicates were processed using GraphPad Prism ${ }^{\circledR}$ 8. Data obtained in the survival assay were summarized as a Kaplan-Meier graph and analyzed statistically using the Log Rank approach. The calculated level of mRNA obtained in this study was prepared as a bar graph and analyzed statistically using one-way ANOVA followed by Tukey HSD post hoc analysis. For all statistical analyses, data were presented as mean \pm S.D, and $p$ values of less than 0.05 were considered statistically significant.

\section{Results}

\subsection{The Lifespan of Drosophila Melanogaster Is Associated with Its Genotypical Characteristics}

Before being used in the experiment, the maximum lifespan of all fly genotypes was assessed. This is very important before conducting a survival test in the presence of the test samples (i.e., drug candidates). Through this experiment, the duration of the experiment can be predicted. Based on our result, Oregon $\mathrm{R}$ had a lifespan of about 60 days and various mutants tested in this study had varying lifespans, with $P G R P-L B^{\Delta}$ having the lowest survival rate (Figure 1). As we can see in Figure 1, immunodeficient mutants (imd1 and the $p s h[1] ; ; \bmod S P[K O])$ can live with lifespans approaching normal flies. Immunodeficient mutant imd 1 is a mutant line lacking a component of immune deficiency (imd) pathway responsible in the regulation of the antibacterial response against Gram-negative bacteria, and $p s h[1] ; \bmod S P[K O])$ is a mutant line lacking persephone (Psh) and modular serine proteases (modSP) that are responsible in the activation of innate immune defenses against Gram-positive bacteria [7]. In this study, fruit fly survival decreases in the absence of PGRP-LB. PGRP-LB is a protein that prevents over-activation of the NF- $\kappa B$ (Imd) pathway, thus the natural immune system of fruit flies (and also mammals, including humans) can be maintained in a homeostatic condition [28].

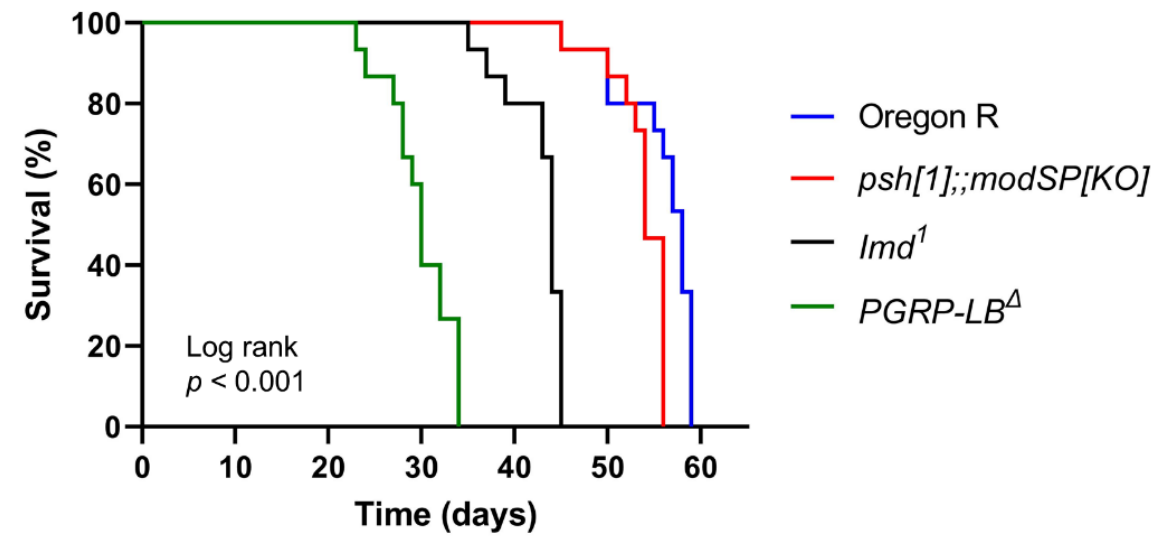

Figure 1. The lifespan of several lines of Drosophila melanogaster. Male flies of different lines were maintained at $25^{\circ} \mathrm{C}$ in normal fly food. The numbers of surviving and dead flies were recorded daily, and fly survivorship was analyzed using a Kaplan-Meier Log Rank approach.

\subsection{Aspirin and Curcumin Improve the Lifespan of Wild-Type Drosophila melanogaster}

In this study, we used two FDA-approved drugs (aspirin and dexamethasone) and two active compounds isolated from natural ingredients (curcumin and EGCG) which have been sold commercially. Pharmacological assessment of drugs/compounds was started using the Oregon R genotype (wildtype). This was carried out to determine the proper concentration of the drugs/compounds to be used in the further experiments. At the same time, this experiment was carried out to examine whether the drug concentrations used in the experiments were at the toxic level or not.

In this experiment, adult Oregon $R$ flies aged 4-7 days old were used as the test flies and drugs/compounds were given orally by food with concentrations depending on each compound. The results demonstrated that drugs/active compounds tested in this study did 
not cause early death in Oregon $\mathrm{R}$ flies at all concentrations tested in this study (Figure 2). What is more, aspirin and curcumin, to a greater extent, could improve the lifespan of Oregon R flies.

A

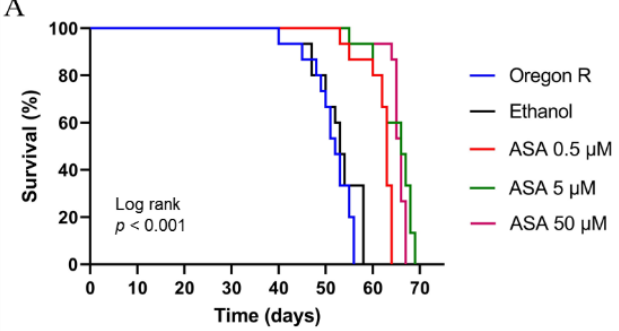

$\mathrm{C}$

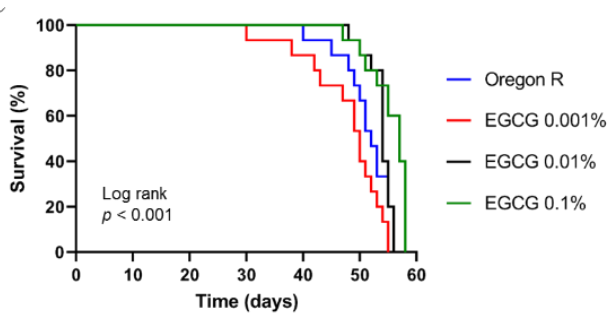

$\mathrm{B}$

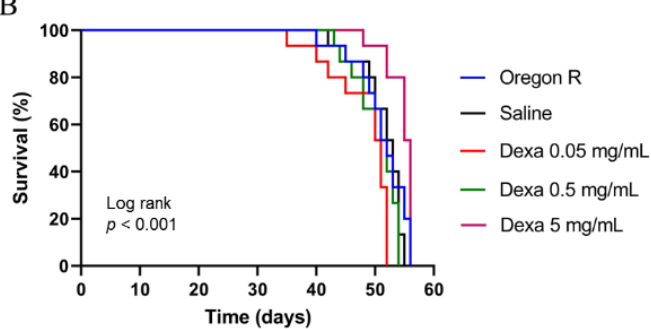

D

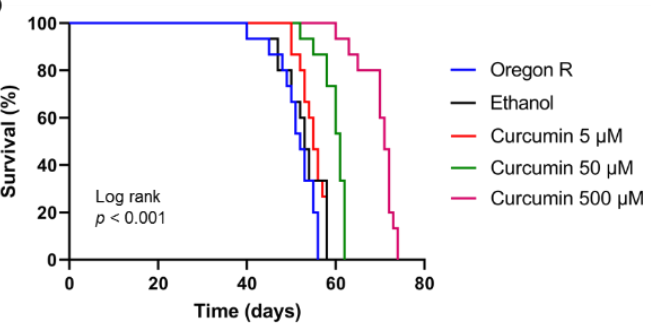

Figure 2. The lifespan of adult males of Oregon $\mathrm{R}$ in the presence or absence of aspirin (A), dexamethasone (B), EGCG (C), and curcumin (D). For each survival experiment, adult males of Oregon $\mathrm{R}$ aged 4-7 days old were maintained at $25^{\circ} \mathrm{C}$ in fly food containing the respective drug/active compounds. The numbers of surviving and dead flies were recorded daily, and fly survivorship was analyzed using a Kaplan-Meier Log Rank approach. ASA, Aspirin; Dexa, Dexamethasone; EGCG; epigallocatechin gallate.

\subsection{Curcumin and EGCG Provide Antibacterial Protection against Staphylococcus aureus}

In this experiment, we used two active compounds isolated from natural ingredients, curcumin and EGCG. These two compounds have been reported for their immunomodulatory activities in mammals [19-21,29,30] as well as their antibacterial activities [31-33]. We have shown that $D$. melanogaster can be used to screen for drug candidates with antibacterial activities [24-27,34,35]. In this study, we extend our study to investigate whether $D$. melanogaster can be used as an initial model organism to screen for immunostimulants and antibacterial drugs candidates before further examination in the mammalian animal models. To do so, we carried out survival analysis on immunodeficient flies (psh[1];;modSP[KO]) in the presence or absence of either curcumin or EGCG, under S. aureus challenge.

Assuming that curcumin exerts immunomodulatory activity via NF- $\mathrm{kB}$ activation (as has been reported in the mammalian animal model), then mutants without a functional NF- $\kappa B$ signaling pathway shall not live longer upon $S$. aureus infection. In this experiment, psh[1];;modSP[KO] mutant flies (this genotype has been known to be susceptible to $S$. aureus infection due to non-functional NF- $k B$-mediated immune reaction) were treated with curcumin at different concentrations. As can be seen in Figure 3A, curcumin can increase the survival of $S$. aureus-infected mutant flies (devoid of Toll-mediated innate immune system) at all tested concentrations used in this study, suggesting that curcumin exerts in vivo antibacterial properties against $S$. aureus. A similar result was obtained using EGCG as a tested compound. EGCG can improve the survival of $S$. aureus-infected psh[1];;modSP[KO] flies, indicating that EGCG also exerts in vivo antistaphylococcal properties in D. melanogaster (Figure 3B). 
A

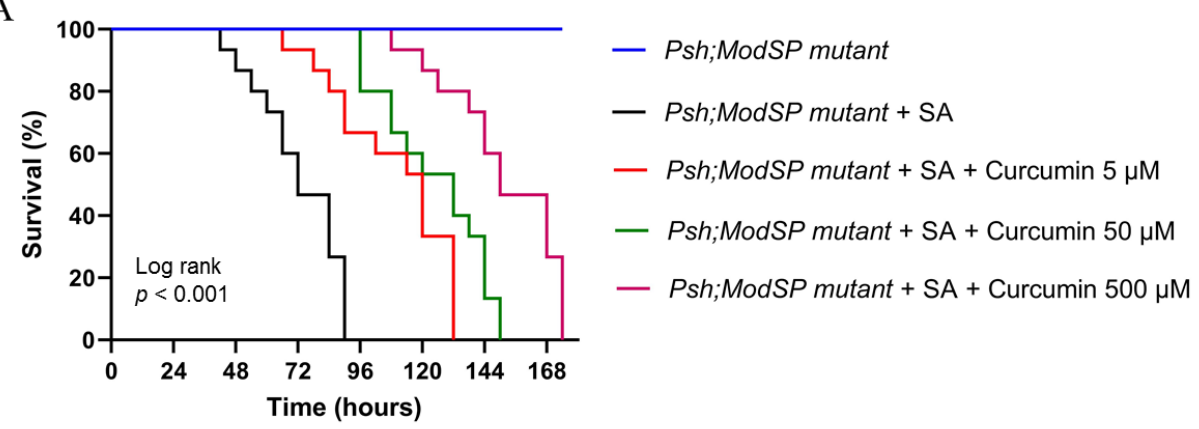

B
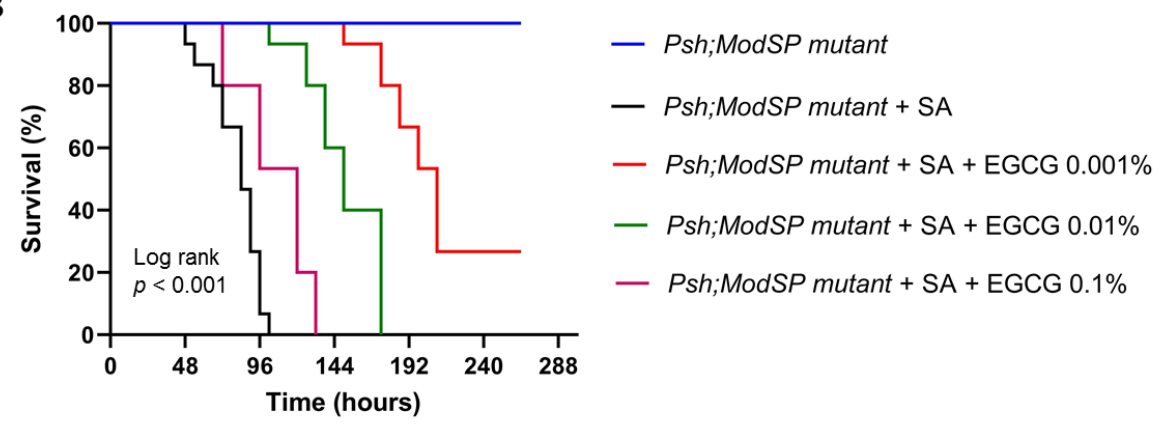

Figure 3. The lifespan of adult males of $p s h[1] ; \operatorname{modSP}[\mathrm{KO}]$ in the presence or absence of curcumin (A) or EGCG (B) under bacterial challenge. For each survival experiment, adult males of $p s h[1] ; ; \operatorname{modSP}[\mathrm{KO}]$ at 4-7 days old were infected with S. aureus and maintained at $29^{\circ} \mathrm{C}$ in fly food containing the respective drug/active compounds. The numbers of surviving and dead flies were recorded daily, and fly survivorship was analyzed using a Kaplan-Meier Log Rank approach. EGCG; epigallocatechin gallate, SA; Staphylococcus aureus.

\subsection{Curcumin and EGCG Downregulate the NF-אB-Mediated Immune Response in D. melanogaster}

To test whether curcumin and EGCG can exert immunomodulatory activity in $D$. melanogaster, we sought to examine the expression profile of NF- $\mathrm{BB}$-related gene in the Oregon $\mathrm{R}$ line of $D$. melanogaster. Activation of the immune system via NF- $\kappa \mathrm{B}$ in the Oregon $\mathrm{R}$ flies is expected to trigger a better host defense against $S$. aureus infection. With this in mind, the additional antibacterial effect of curcumin shall promote a better fly survival postinfection with $S$. aureus than that seen in the $p s h[1] ;$ modSP[KO] NF-kB-immunodeficient mutant. However, in this study, we observed that the expression of Drs, an antimicrobial peptide released in response to Gram-positive infection, was downregulated in the presence of curcumin at all tested concentrations (Figure 4A) while the expression of this gene was modulated in a concentration-dependent manner upon EGCG treatment (Figure 4B) in Oregon $\mathrm{R}$ flies. These results indicate that curcumin and EGCG exert antibacterial activity against $S$. aureus as well as immunomodulatory activity, which in the end will influence the phenotypical feature observed in the infected mutant flies.

\subsection{Aspirin and Dexamethasone Improve the Lifespan of Flies with Hyperactive Immune Phenotype}

In this study, we used two FDA-approved drugs, aspirin and dexamethasone, that have been reported to yield immunosuppressive activity [11,36-38]. We tested the immunosuppressant activity of aspirin and dexamethasone using $P G R P-L B^{\Delta}$ flies with NF$\mathrm{KB}$-associated immune hyperactivation (autoinflammatory model). Survival testing was carried out to see whether the concentration of aspirin or dexamethasone used in this study could reduce the risk of early death in the PGRP- $L B^{\Delta}$ flies. Adult $P G R P-L B^{\Delta}$ aged 2-4 days old were used as test flies and drugs were orally given to flies, with concentrations depending on each test compound. As can be seen in Figure 5, the survival of PGRP-LB ${ }^{\Delta}$ was improved dramatically upon drug treatment, indicating that aspirin or dexamethasone can 
ameliorate the early death phenotype of $P G R P-L B^{\Delta}$ flies at the tested concentrations. These results further implicate that both drugs might exert their immunosuppressive activity via inhibition of the NF-kB pathway of D. melanogaster.

A

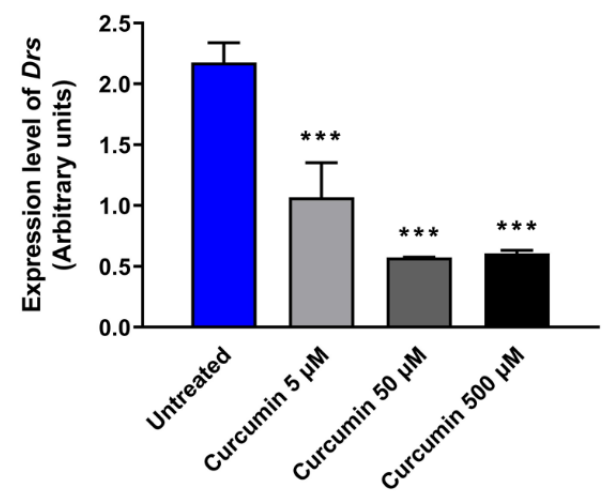

B

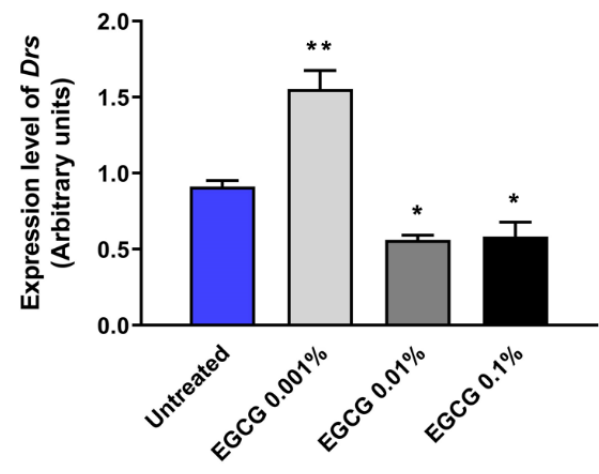

Figure 4. Expression of Drs in adult males of Oregon R in the presence or absence of curcumin (A) or EGCG (B). For each experiment, adult males of Oregon $R$ at $4-7$ days old were maintained at $25^{\circ} \mathrm{C}$ in fly food containing the respective drug/active compounds. These flies were subjected to total RNA isolation and subsequently followed by RT-qPCR for quantification of Drs mRNA level. The expression level of $r p 49$ was used as the reference control. EGCG, epigallocatechin gallate; ${ }^{*} p<0.05$, ** $p<0.01,{ }^{* * *} p<0.001$.

A

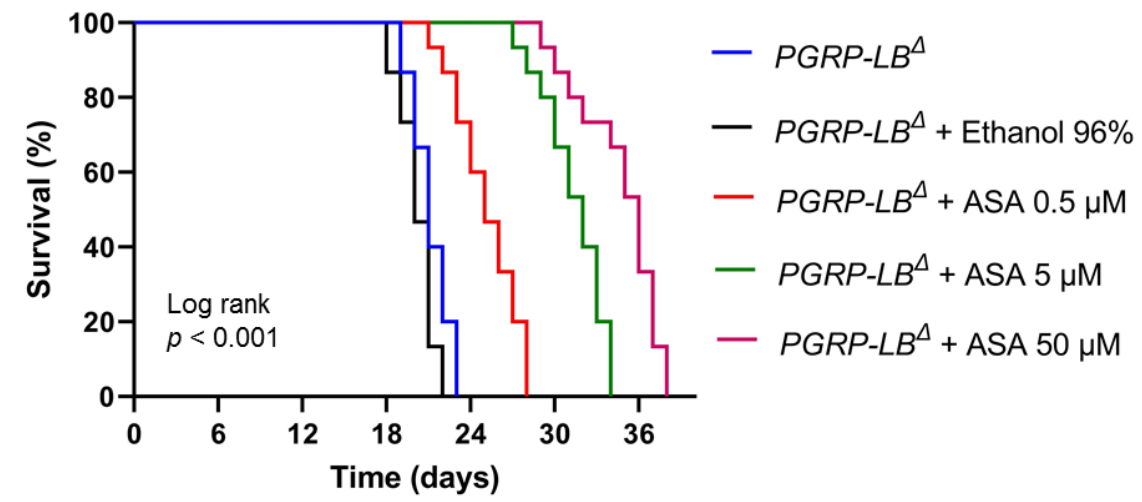

$\mathrm{B}$

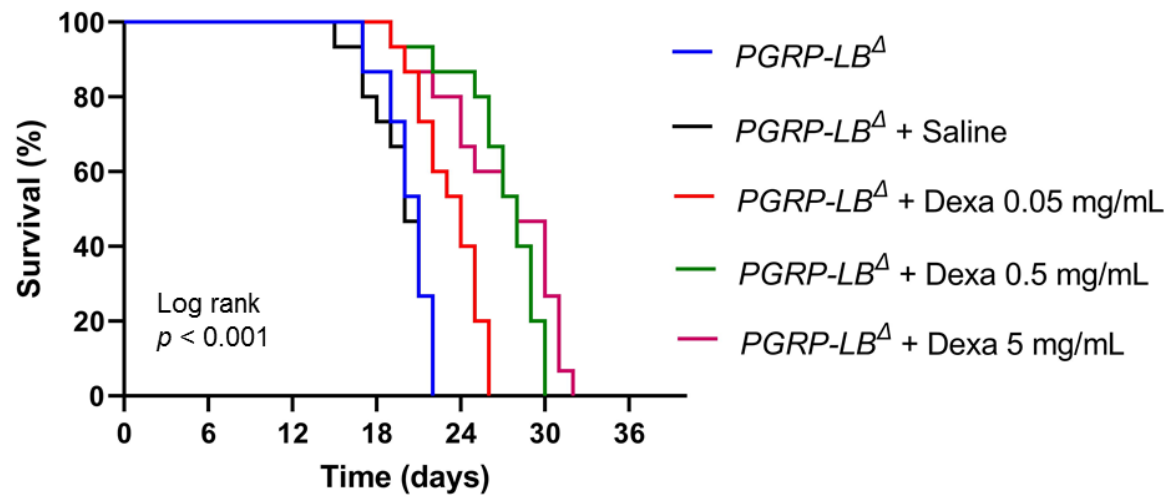

Figure 5. Survivorship of adult males of $P G R P-L B^{\Delta}$ in the presence or absence of aspirin (A) or dexamethasone (B). For each survival experiment, adult males of $P G R P-L B^{\Delta}$ at 2-4 days old were maintained at $25^{\circ} \mathrm{C}$ in fly food containing the respective drug/active compounds. The numbers of surviving and dead flies were recorded daily, and fly survivorship was analyzed using a KaplanMeier Log Rank approach. ASA, Aspirin; Dexa, Dexamethasone. 


\subsection{Downregulation of Innate Immune-Related Target Genes in D. melanogaster by Aspirin and Dexamethasone}

To test whether dexamethasone or aspirin can downregulate the expression of NF- $\mathrm{kB}$ related genes, we carried out an RT-qPCR experiment using RNA samples of $P G R P-L B^{\Delta}$ treated with these drugs, separately. Genes measured in this study were Drs (Toll pathway) and Dpt (Imd pathway). These two genes represent the immune system of the Toll and Imd pathways, two main pathways in the fruit fly immune system that are homologous to the NF-KB pathway of humans. The results (Figure 6) demonstrated that ingestion of dexamethasone, but not aspirin, reduced the expression of Drs. In addition, both aspirin and dexamethasone can suppress the expression of Dpt in D. melanogaster, further supporting the notion that these drugs might improve the survival of $P G R P-L B^{\Delta}$ flies via the inhibition of the NF- $\mathrm{kB}$ (Imd) pathway of D. melanogaster.

A

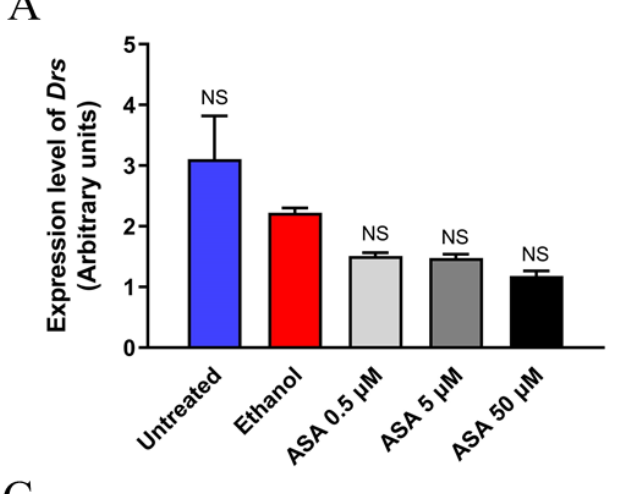

$\mathrm{C}$

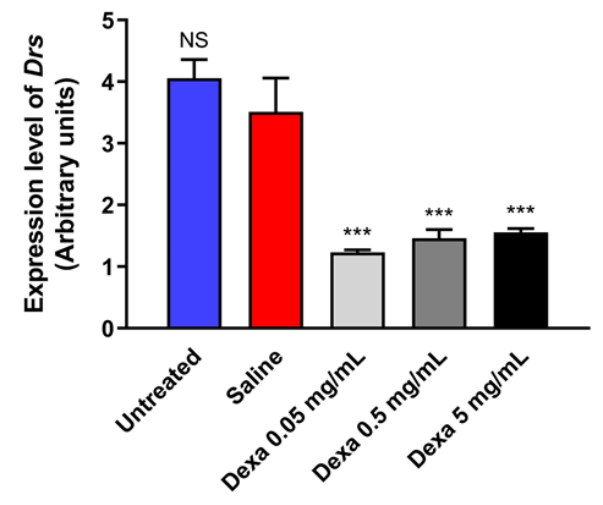

B

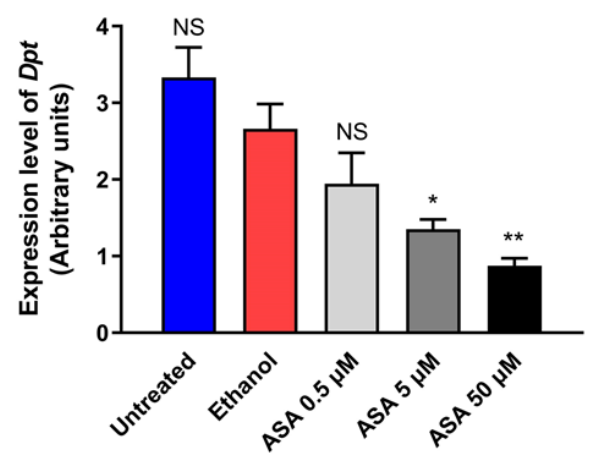

$\mathrm{D}$

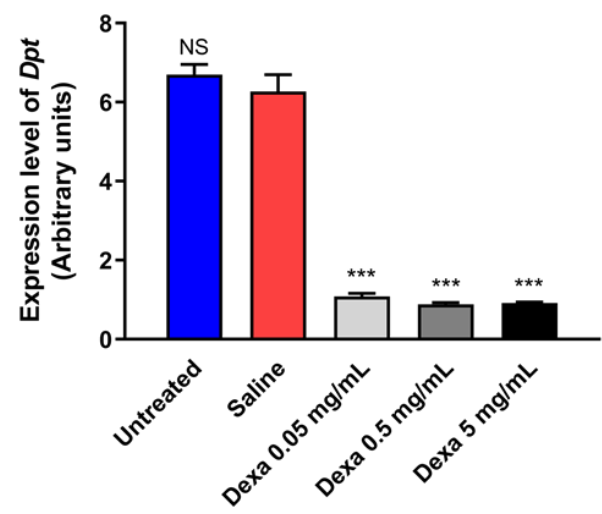

Figure 6. Expression of Drs and Dpt in the adult males of $P G R P-L B^{\Delta}$ in the presence or absence of aspirin $(\mathbf{A}, \mathbf{B})$ or dexamethasone $(\mathbf{C}, \mathbf{D})$. For each experiment, adult males of $P G R P-L B^{\Delta}$ at $2-4$ days old were maintained at $25^{\circ} \mathrm{C}$ in fly food containing the respective drugs. These flies were subjected to total RNA isolation and subsequently followed by RT-qPCR for quantification of Drs and Dpt mRNA levels. The expression level of $r p 49$ was used as the reference control. ASA, Aspirin; Dexa, Dexamethasone; NS, Non-Significant; ${ }^{*} p<0.05 ;{ }^{* *} p<0.01$; ${ }^{* * *} p<0.001$.

\section{Discussion}

In this study, we demonstrated that $D$. melanogaster is a prospective model to screen immunomodulatory drug candidates and at the same time also demonstrate whether such candidates also exert antibacterial potency. We observed that curcumin and EGCG showed a protective signature against bacterial infection in flies lacking Toll-mediated immune responses. Furthermore, dexamethasone and aspirin could suppress the immune activities of $P G R P-L B^{\Delta}$ mutant flies with the hyperactivated immune system and, therefore, improve their survival. All the tested substances were able to modulate the expression level of genes related to the immune system. 
In this study, we examined the immunomodulatory activities of two synthetic drugs and two natural products, which have been previously reported to exert such effect in the mammalian animal models [37,39-41]. Our results demonstrated that the potentials of mammalian-proven immunomodulatory drugs/compounds can also be seen in the invertebrate D. melanogaster model, suggesting that there is a high chance that D. melanogaster can be used as an appropriate model to screen immunomodulatory substances either from a repurposed drug or from natural compounds before further tests on the mammalian animal models in the drug discovery pipeline.

Curcumin has been known to induce the activation of innate (macrophages, neutrophils, natural killer cells, and dendritic cells) as well as adaptive (T cells and B cells) immune responses. Intriguingly, curcumin has also been reported to suppress the expression of several pro-inflammatory cytokines such as interleukins (IL-1, IL-2, IL-6, IL-8, and IL-12), TNF- $\alpha$, and chemokines via the inhibition of the transcription factor NF- $\mathrm{B}$ activation [40]. Furthermore, a previous report demonstrated the immunomodulation of T cell activation by EGCG [41] but remains inconclusive on the modulation of NF- $\mathrm{KB}$ signaling pathways. In this study, we observed interesting results in the expression profile of Drs in the Oregon $\mathrm{R}$ flies upon incubation with EGCG containing fly food. The presence of a low concentration of EGCG (0.001\%) in the fly food could stimulate the expression of Drs in the Oregon R flies. On the contrary, higher concentrations of EGCG $(0.01 \%$ and $0.1 \%)$ in the fly food were resulted in the downregulation of Drs expression. While the reason remains unknown, our result suggested that EGCG could modulate fly immune system in a dose-dependent manner and the resulting effect can differ considerably. This data might provide a hint regarding the conflicting results on the immunomodulatory effect of EGCG in the mammals.

As good examples of well-known pharmaceuticals, aspirin and dexamethasone have been reported to yield immunosuppressive effects on the innate and adaptive immune responses [37,39]. Aspirin can suppress the neutrophil-mediated immunity by decreasing their extravasation, a distinctive step in the innate immunity, and exert a dose-dependent inhibition of $\mathrm{T}$ cells proliferation as a part of its negative effect on the adaptive immune system [39]. Moreover, dexamethasone has been reported to negatively modulate the activity of $\mathrm{T}$ cells leading to reduction of naïve $\mathrm{T}$ cell proliferation and differentiation. This is mainly achieved via alteration of the CD28 co-stimulatory pathway [37].

An interesting result was also observed in the survival of $P G R P-L B^{\Delta}$ flies. The loss of PGRP-LB has resulted in the decline of survival rate of D. melanogaster. Based on previous report by Paredes et al. (2011), PGRP-LB provides antibacterial protection against gut innocuous infection and is important in the homeostatic maintenance of the Imd pathway. They observed that the loss of PGRP-LB diminishes such protection, leading to immediate death upon bacterial challenge [28]. The authors suggested that the cause of early death phenotype probably resulted from the overactivation of the Imd pathway, either due to bacterial challenge or the presence of immune-stimulatory ligands such as peptidoglycans released from dead bacteria. Intriguingly, we did not use live bacteria or any bacterial component in the assay involving $P G R P-L B^{\Delta}$ flies. The reason for this early death phenotype remains uncertain, but it is tempting to speculate that this might not relate to the presence of bacterial components in the fly food, as we used the same fly food for immunodeficient fly lines (psh[1];; $\operatorname{modSP}[\mathrm{KO}]$ and $\left.i m d^{1}\right)$ as well.

The results reported in the mammalian pre-clinical studies, to a greater extent, are similar to what we observed in this study, thus reinforcing the idea that a simplified invertebrate model such as D. melanogaster may respond in a similar fashion upon the introduction of immunomodulatory agents. While it is quite early to make assumptions about the detailed mechanisms of action of the tested drugs in D. melanogaster without carrying out further experiments, the results of this study warranted subsequent investigations.

To improve the animal welfare, replacing the high-order animal model with a loworder animal model is strongly recommended, whenever possible [42]. In this case, the use of fruit fly $D$. melanogaster has attracted numerous innovations and opened new horizons 
in the study of human diseases and drug discovery $[6,9,10]$, including in the study of coronavirus disease (COVID-19) [43-45]. Invertebrate model organisms, such as the fruit fly, are deemed to feel less pain and distress than the mammalian models, as suggested by the National Centre for the Replacement Refinement \& Reduction of Animals in Research (NC3R) [42,46,47]. However, it is important to note that the replacement effort should ensure that the quality of scientific value produced by the alternative model is scientifically sufficient. Therefore, validation studies are important to assure that the alternative model can generate reliable knowledge.

Fruit flies have been proven as a good model system for several human diseases $[6,9,48,49]$ and in some cases have been successfully applied as a model organism in the screening and evaluation of drug candidates for treating multiple diseases, including cancer [50,51], infection [52], and neurodegenerative diseases [53,54]. Based on this study, we proposed the use of $D$. melanogaster in the initial screening of prospective immunomodulators, especially the ones that act on the NF- $\mathrm{kB}$ pathway, prior to further checking on safety, doses, and other appropriate pre-clinical features using the mammalian model system. This is to prevent unnecessary economical loss due to the excessive use of mammalian animals in the initial testing of drug candidates as well as to manage animal welfare while achieving the in vivo results at its best condition.

\section{Conclusions}

In this research, we demonstrated, for the first time, the potential use of D. melanogaster as an in vivo pre-clinical model organism in the initial screening of drug candidates with immunomodulatory activities. It would be essential to elucidate the characteristics of immunomodulatory activities of drug candidates and the impact of such phenotypical signatures to other physiological characteristics. Our Drosophila model system can serve as an in vivo high-throughput screening platform to investigate the immunomodulatory potential of certain samples before testing in higher mammalian model system. Such effort will help to reduce the number of mammalian animals used in the study and in time, will reduce the cost of pre-clinical studies required in the drug discovery. In addition, using this in vivo model system, one might observe additional pharmacological effects (for example antibacterial activity) and be able to predict the potential adverse or toxicity effect at the whole-body level, adding beneficial features offered in the in vitro experiments.

Author Contributions: Conceptualization, F.N., S.S. and M.A.B.; methodology, F.N.; formal analysis, F.N.; investigation, F.N., R.A.R., N.R., R.A.K. and N.R.R.; resources, F.N., S.S., M.A.B., R.Y. and E.W.; writing — original draft preparation, F.N.; writing-review and editing, F.N., S.S. and M.A.B.; supervision, F.N., S.S. and M.A.B.; project administration, N.R., R.A.K., R.A.R. and N.R.R.; funding acquisition, F.N., S.S. and M.A.B. All authors have read and agreed to the published version of the manuscript.

Funding: This research was financially supported by PDUPT research grant to F.N, S.S., M.A.B (Contract No. 752/UN4.22/PT.02.00/2021) from Directorate General of Higher Education, Ministry of Education, Culture, Research, and Technology, Indonesia.

Institutional Review Board Statement: Not applicable.

Informed Consent Statement: Not applicable.

Data Availability Statement: Data is contained within the article.

Acknowledgments: We are grateful to Yoshinobu Nakanishi and Takayuki Kuraishi (Kanazawa University, Japan) for their help in providing Drosophila lines used in this study. We also would like to thank to Isra Wahid (Faculty of Medicine, Hasanuddin University) for his generous support in the use of research facilities at his laboratory.

Conflicts of Interest: The authors declare no conflict of interest. 


\section{References}

1. Atanasov, A.G.; Zotchev, S.B.; Dirsch, V.M.; International Natural Product Sciences Taskforce; Supuran, C.T. Natural products in drug discovery: Advances and opportunities. Nat. Rev. Drug Discov. 2021, 20, 200-216. [CrossRef]

2. Ganeshpurkar, A.; Saluja, A.K. Experimental animal models used for evaluation of potential immunomodulators: A mini review. Bull. Fac. Pharm. Cairo Univ. 2017, 55, 211-216. [CrossRef]

3. Shi, J.; Weng, J.-H.; Mitchison, T.J. Immunomodulatory drug discovery from herbal medicines: Insights from organ-specific activity and xenobiotic defenses. eLife 2021, 10, e73673. [CrossRef] [PubMed]

4. Chaplin, D.D. Overview of the immune response. J. Allergy Clin. Immunol. 2010, 125, S3-S23. [CrossRef] [PubMed]

5. Qu, X.; Tang, Y.; Hua, S. Immunological Approaches Towards Cancer and Inflammation: A Cross Talk. Front. Immunol. 2018, 9, 563. [CrossRef]

6. Pandey, U.B.; Nichols, C.D. Human disease models in Drosophila melanogaster and the role of the fly in therapeutic drug discovery. Pharmacol. Rev. 2011, 63, 411-436. [CrossRef]

7. Buchon, N.; Silverman, N.; Cherry, S. Immunity in Drosophila melanogaster-From microbial recognition to whole-organism physiology. Nat. Rev. Immunol. 2014, 14, 796-810. [CrossRef]

8. Lemaitre, B.; Hoffmann, J. The host defense of Drosophila melanogaster. Annu. Rev. Immunol. 2007, 25, 697-743. [CrossRef]

9. Nainu, F.; Nakanishi, Y.; Shiratsuchi, A. Fruit fly as a model organism in the study of human diseases and drug discovery. J. Cent. Med. Educ. Sapporo Med. Univ. 2019, 10, 21-32.

10. Fernández-Hernández, I.; Scheenaard, E.; Pollarolo, G.; Gonzalez, C. The translational relevance of Drosophila in drug discovery. EMBO Rep. 2016, 17, 471-472. [CrossRef]

11. Morris, T.; Stables, M.; Hobbs, A.; de Souza, P.; Colville-Nash, P.; Warner, T.; Newson, J.; Bellingan, G.; Gilroy, D.W. Effects of Low-Dose Aspirin on Acute Inflammatory Responses in Humans. J. Immunol. 2009, 183, 2089-2096. [CrossRef] [PubMed]

12. Graham, N.M.; Burrell, C.J.; Douglas, R.M.; Debelle, P.; Davies, L. Adverse effects of aspirin, acetaminophen, and ibuprofen on immune function, viral shedding, and clinical status in rhinovirus-infected volunteers. J. Infect. Dis. 1990, 162, 1277-1282. [CrossRef]

13. Brox, R.; Hackstein, H. Physiologically relevant aspirin concentrations trigger immunostimulatory cytokine production by human leukocytes. PLoS ONE 2021, 16, e0254606. [CrossRef] [PubMed]

14. Zhang, X.; Chang, A.; Zou, Y.; Xu, H.; Cui, J.; Chen, Z.; Li, Y.; Du, Y.; Wu, J.; Yu, J.; et al. Aspirin Attenuates Cardiac Allograft Rejection by Inhibiting the Maturation of Dendritic Cells via the NF-kB Signaling Pathway. Front. Pharmacol. 2021, 12, 706748. [CrossRef] [PubMed]

15. Bancos, S.; Bernard, M.P.; Topham, D.J.; Phipps, R.P. Ibuprofen and other widely used non-steroidal anti-inflammatory drugs inhibit antibody production in human cells. Cell. Immunol. 2009, 258, 18-28. [CrossRef] [PubMed]

16. Joekel, D.E.; Deplazes, P. Optimized dexamethasone immunosuppression enables Echinococcus multilocularis liver establishment after oral egg inoculation in a rat model. Exp. Parasitol. 2017, 180, 27-32. [CrossRef]

17. Thachil, A.J.; Shaw, D.P.; Nagaraja, K.V. Effects of Dexamethasone Immunosuppression on Turkey Clostridial Dermatitis. Avian Dis. 2014, 58, 433-436. [CrossRef]

18. Hundakova, A.; Leva, L.; Toman, M.; Knotek, Z. A ferret model of immunosuppression induced with dexamethasone. Vet. Immunol. Immunopathol. 2022, 243, 110362. [CrossRef]

19. Yuandani; Jantan, I.; Rohani, A.S.; Sumantri, I.B. Immunomodulatory Effects and Mechanisms of Curcuma Species and Their Bioactive Compounds: A Review. Front. Pharmacol. 2021, 12, 643119. [CrossRef]

20. Catanzaro, M.; Corsini, E.; Rosini, M.; Racchi, M.; Lanni, C. Immunomodulators Inspired by Nature: A Review on Curcumin and Echinacea. Molecules 2018, 23, 2778. [CrossRef]

21. Kuo, C.L.; Chen, T.S.; Liou, S.Y.; Hsieh, C.C. Immunomodulatory effects of EGCG fraction of green tea extract in innate and adaptive immunity via T regulatory cells in murine model. Immunopharmacol. Immunotoxicol. 2014, 36, 364-370. [CrossRef] [PubMed]

22. Huang, A.-C.; Cheng, H.-Y.; Lin, T.-S.; Chen, W.-H.; Lin, J.-H.; Lin, J.-J.; Lu, C.-C.; Chiang, J.-H.; Hsu, S.-C.; Wu, P.-P.; et al. Epigallocatechin Gallate (EGCG), Influences a Murine WEHI-3 Leukemia Model In Vivo Through Enhancing Phagocytosis of Macrophages and Populations of T- and B-Cells. In Vivo 2013, 27, 627-634.

23. Saleh, F.; Raghupathy, R.; Asfar, S.; Oteifa, M.; Al-Saleh, N. Analysis of the effect of the active compound of green tea (EGCG) on the proliferation of peripheral blood mononuclear cells. BMC Complement. Altern. Med. 2014, 14, 322. [CrossRef] [PubMed]

24. Nainu, F.; Asri, R.M.; Arsyad, A.; Manggau, M.A.; Amir, M.N. In vivo antibacterial activity of green algae Ulva reticulata against Staphylococcus aureus in Drosophila model of infection. Pharmacogn. J. 2018, 10, 993-997. [CrossRef]

25. Ahsan, M.; Gonsales, A.V.; Sartini, S.; Wahyudin, E.; Nainu, F. In vivo anti-staphylococcal activity of roselle (Hibiscus sabdariffa L.) calyx extract in Drosophila model of infection. J. Herbmed Pharmacol. 2019, 8, 41-46. [CrossRef]

26. Nainu, F.; Djide, M.N.; Subehan, S.; Sartini, S.; Roska, T.P.; Salim, E.; Kuraishi, T. Protective Signatures of Roselle (Hibiscus sabdariffa L.) Calyx Fractions against Staphylococcus aureus in Drosophila Infection Model. HAYATI J. Biosci. 2020, 27, 306-313. [CrossRef]

27. Nainu, F.; Asri, R.M.; Djide, M.N.; Ahsan, M.; Arfiansyah, R.; Sartini, S.; Alam, G. Protective effect of green algae Ulva reticulata against Pseudomonas aeruginosa in Drosophila infection model. HAYATI J. Biosci. 2019, 26, 163-171. [CrossRef] 
28. Paredes, J.C.; Welchman, D.P.; Poidevin, M.; Lemaitre, B. Negative Regulation by Amidase PGRPs Shapes the Drosophila Antibacterial Response and Protects the Fly from Innocuous Infection. Immunity 2011, 35, 770-779. [CrossRef]

29. Kim, G.Y.; Kim, K.H.; Lee, S.H.; Yoon, M.S.; Lee, H.J.; Moon, D.O.; Lee, C.M.; Ahn, S.C.; Park, Y.C.; Park, Y.M. Curcumin inhibits immunostimulatory function of dendritic cells: MAPKs and translocation of NF- $\mathrm{kB}$ as potential targets. J. Immunol. 2005, 174, 8116-8124. [CrossRef]

30. Tallei, T.E.; Fatimawali; Niode, N.J.; Idroes, R.; Zidan, B.M.R.M.; Mitra, S.; Celik, I.; Nainu, F.; Ağagündüz, D.; Bin Emran, T.; et al. A Comprehensive Review of the Potential Use of Green Tea Polyphenols in the Management of COVID-19. Evid.-Based Complement. Altern. Med. 2021, 2021, 7170736. [CrossRef]

31. Steinmann, J.; Buer, J.; Pietschmann, T.; Steinmann, E. Anti-infective properties of epigallocatechin-3-gallate (EGCG), a component of green tea. Br. J. Pharmacol. 2013, 168, 1059-1073. [CrossRef] [PubMed]

32. Moghadamtousi, S.Z.; Kadir, H.A.; Hassandarvish, P.; Tajik, H.; Abubakar, S.; Zandi, K. A review on antibacterial, antiviral, and antifungal activity of curcumin. BioMed Res. Int. 2014, 2014, 186864. [CrossRef] [PubMed]

33. Wang, J.; Zhou, X.; Li, W.; Deng, X.; Deng, Y.; Niu, X. Curcumin protects mice from Staphylococcus aureus pneumonia by interfering with the self-assembly process of $\alpha$-hemolysin. Sci. Rep. 2016, 6, 28254. [CrossRef] [PubMed]

34. Anisa, A.N.; Rahmasari, M.; Roska, T.P.; Arfiansyah, R.; Sartini, S.; Djide, M.N.; Harapan, H.; Nainu, F. Antimicrobial Effect of Roselle (Hibiscus sabdariffa L.) Water Fraction against Pseudomonas aeruginosa using Drosophila Infection Model. Biointerface Res. Appl. Chem. 2021, 11, 12877-12885.

35. Sukarsih, Y.; Arfiansyah, R.; Roska, T.P.; Murdifin, M.; Kasim, S.; Nainu, F. Protective Effect of Ethanol Extract of Legundi (Vitex trifolia L.) Leaves against Staphylococcus aureus in Drosophila Infection Model. Biointerface Res. Appl. Chem. 2021, 11, 13989-13996.

36. Østensen, M.; Khamashta, M.; Lockshin, M.; Parke, A.; Brucato, A.; Carp, H.; Doria, A.; Rai, R.; Meroni, P.; Cetin, I.; et al. Anti-inflammatory and immunosuppressive drugs and reproduction. Arthritis Res. Ther. 2006, 8, 209. [CrossRef]

37. Giles, A.J.; Hutchinson, M.-K.N.D.; Sonnemann, H.M.; Jung, J.; Fecci, P.E.; Ratnam, N.M.; Zhang, W.; Song, H.; Bailey, R.; Davis, D.; et al. Dexamethasone-induced immunosuppression: Mechanisms and implications for immunotherapy. J. ImmunoTher. Cancer 2018, 6, 51. [CrossRef]

38. Coutinho, A.E.; Chapman, K.E. The anti-inflammatory and immunosuppressive effects of glucocorticoids, recent developments and mechanistic insights. Mol. Cell. Endocrinol. 2011, 335, 2-13. [CrossRef]

39. Hussain, M.; Javeed, A.; Ashraf, M.; Zhao, Y.; Mukhtar, M.M.; Rehman, M.U. Aspirin and immune system. Int. Immunopharmacol. 2012, 12, 10-20. [CrossRef]

40. Jagetia, G.C.; Aggarwal, B.B. "Spicing Up" of the Immune System by Curcumin. J. Clin. Immunol. 2007, 27, 19-35. [CrossRef]

41. Pae, M.; Wu, D. Immunomodulating effects of epigallocatechin-3-gallate from green tea: Mechanisms and applications. Food Funct. 2013, 4, 1287-1303. [CrossRef] [PubMed]

42. Gorzalczany, S.B.; Rodriguez Basso, A.G. Strategies to apply 3Rs in preclinical testing. Pharmacol. Res. Perspect. 2021, 9, e00863. [CrossRef] [PubMed]

43. Nainu, F.; Rahmatika, D.; Emran, T.B.; Harapan, H. Potential Application of Drosophila melanogaster as a Model Organism in COVID-19-Related Research. Front. Pharmacol. 2020, 11, 588561. [CrossRef] [PubMed]

44. van de Leemput, J.; Han, Z. Drosophila, a powerful model to study virus-host interactions and pathogenicity in the fight against SARS-CoV-2. Cell Biosci. 2021, 11, 110. [CrossRef] [PubMed]

45. Herrera, P.; Cauchi, R.J. ACE and ACE2: Insights from Drosophila and implications for COVID-19. Heliyon 2021, 7, e08555. [CrossRef]

46. Burden, N.; Chapman, K.; Sewell, F.; Robinson, V. Pioneering better science through the 3Rs: An introduction to the national centre for the replacement, refinement, and reduction of animals in research (NC3Rs). J. Am. Assoc. Lab. Anim. Sci. 2015, 54, 198-208.

47. Prescott, M.J.; Lidster, K. Improving quality of science through better animal welfare: The NC3Rs strategy. Lab Anim. 2017, 46, 152-156. [CrossRef]

48. Nainu, F.; Salim, E.; Asri, R.M.; Hori, A.; Kuraishi, T. Neurodegenerative disorders and sterile inflammation: Lessons from a Drosophila model. J. Biochem. 2019, 166, 213-221. [CrossRef]

49. Ugur, B.; Chen, K.; Bellen, H.J. Drosophila tools and assays for the study of human diseases. Dis. Models Mech. 2016, 9, 235-244. [CrossRef]

50. Willoughby, L.F.; Schlosser, T.; Manning, S.A.; Parisot, J.P.; Street, I.P.; Richardson, H.E.; Humbert, P.O.; Brumby, A.M. An in vivo large-scale chemical screening platform using Drosophila for anti-cancer drug discovery. Dis. Models Mech. 2013, 6, 521-529. [CrossRef]

51. Das, T.; Cagan, R. Drosophila as a novel therapeutic discovery tool for thyroid cancer. Thyroid 2010, 20, 689-695. [CrossRef] [PubMed]

52. Tzelepis, I.; Kapsetaki, S.E.; Panayidou, S.; Apidianakis, Y. Drosophila melanogaster: A first step and a stepping-stone to anti-infectives. Curr. Opin. Pharmacol. 2013, 13, 763-768. [CrossRef] [PubMed]

53. Maitra, U.; Ciesla, L. Using Drosophila as a platform for drug discovery from natural products in Parkinson's disease. MedChemComm 2019, 10, 867-879. [CrossRef] [PubMed]

54. Newman, T.; Sinadinos, C.; Johnston, A.; Sealey, M.; Mudher, A. Using Drosophila models of neurodegenerative diseases for drug discovery. Expert Opin. Drug Discov. 2011, 6, 129-140. [CrossRef] 